\title{
Photodegradation of atmospheric chromophores: changes in oxidation state and photochemical reactivity
}

\author{
Zhen Mu, Qingcai Chen, Lixin Zhang, Dongjie Guan, and Hao Li \\ School of Environmental Science and Engineering, Shaanxi University of Science and Technology, Xi' an, 710021, China
}

Correspondence: Qingcai Chen (chenqingcai@sust.edu.cn)

Received: 27 November 2020 - Discussion started: 8 December 2020

Revised: 21 June 2021 - Accepted: 1 July 2021 - Published: 4 August 2021

\begin{abstract}
Atmospheric chromophoric organic matter (COM) plays a fundamental role in photochemistry and aerosol aging. However, the effects of photodegradation on chemical components and photochemical reactivity of COM remain unresolved. Here, we report the potential effects of photodegradation on carbon contents, optical properties, fluorophore components and photochemical reactivity in aerosol. After $7 \mathrm{~d}$ of photodegradation, fluorescent intensity and the absorption coefficient of COM decrease by $71.4 \%$ and $32.0 \%$, respectively. Photodegradation makes a difference to the chemical component of chromophore and the degree of aerosol aging. Low-oxidation humic-like substance (HULIS) is converted into high-oxidation HULIS due to photooxidation. Photodegradation also changes the photochemical reactivity. The generation of triplet-state $\mathrm{COM}\left({ }^{3} \mathrm{COM}^{*}\right)$ decreases slightly in ambient particulate matter (ambient PM) but increases in primary organic aerosol (POA) following photodegradation. The results highlight that the opposite effect of photodegradation on photochemical reactivity in POA and ambient PM. However, the generation of singlet-oxygen $\left({ }^{1} \mathrm{O}_{2}\right)$ decreases obviously in POA and ambient PM, which could be attributed to photodegradation of precursors of ${ }^{1} \mathrm{O}_{2}$. The combination of optical property, chemical component and reactive oxygen species has an important impact on the air quality. The new insights on COM photodegradation in aerosol reinforce the importance of studying dissolved organic matter (DOM) related with the photochemistry and aerosol aging.
\end{abstract}

\section{Introduction}

Atmospheric chromophoric organic matter (COM) is an important component of biomass combustion emissions and secondary organic aerosol (SOA) (Andreae and Gelencser, 2006; Budisulistiorini et al., 2017; Graber and Rudich, 2006; Zappoli et al., 1999). COM has a significant absorption in the near-ultraviolet and visible region (Rosario-Ortiz and Canonica, 2016; Cheng et al., 2016), and photochemistry of COM has a significant impact on air quality (Zhao et al., 2013; Jo et al., 2016). Therefore, simulation and evaluation of COM photochemistry are both necessary for understanding aerosol aging.

Photodegradation changes the optical properties of COM (Atkinson et al., 2006; Carlton et al., 2007; Lee et al., 2013; Murphy et al., 2013). Zhong and Jang (2014) reported that mass absorption coefficients (MAC) of wood-burning organic matter $(\mathrm{OM})$ decreased by $41 \%$ on average. Conjugated aromatic rings, phenols and hydroxylated aromatic phenols were the main components in wood-burning OM and these components were photo-bleaching. Lee et al. (2014) reported that the MAC of secondary organic aerosol (SOA) continued to decrease in the UV-Vis spectral range. Photodegradation has a significant effect on the chemical components of COM. On the one hand, photodegradation could cause decomposition of COM and the decomposed COM is characterized by smaller molecule weight, lower volatility and higher oxidation degree (Grieshop et al., 2009). On the other hand, COM could be generated through the photochemical reaction. For example, oligomeric COM generated by a mixture of anthracene and naphthalene suspensions through self-oxidation under solar irradiation and photooxidation of aromatic isoprene oxides were an important source of high-molecular-weight COM (Altieri et al., 2006; 
Altieri et al., 2008; Haynes et al., 2019; Holmes and Petrucci, 2006; Perri et al., 2009). SOA may have a more significant light absorption than primary organic aerosol (POA) in the short-wavelength visible and near-UV range (Zhong and Jang, 2014; Saleh et al., 2013; Harrison et al., 2020). Photodegradation plays an important role in the components and properties of COM and thereby changes photochemical activity. There are limited studies that comprehensively explore the characteristics of COM photodegradation in aerosol.

Photochemistry of COM largely determines the aerosol aging (Mang et al., 2008). On the one hand, COM is a photosensitive reactant in photochemical reaction in aerosol. For example, COM could be oxidized by hydroxyl radicals (.OH). Humic-like substance (HULIS) with complex functional groups has significant contribution to photochemistry (George et al., 2015; Nebbioso and Piccolo, 2013; Wenk et al., 2013). The formation of polyols can be attributed to photooxidation of isoprene, and the reaction was initiated by .OH (Claeys et al., 2004; Zhao et al., 2015). On the other hand, COM participates in photochemical reaction indirectly through generating reactive intermediates, transferring energy and involving electrons. High-energy singlet-state COM $\left({ }^{1} \mathrm{COM}^{*}\right)$ is excited and deactivates rapidly through emitting photon (fluorescence) and intersystem crossing (triplet-state $\left({ }^{3} \mathrm{COM}^{*}\right)$ generation). ${ }^{3} \mathrm{COM}^{*}$ can generate reactive oxygen species (ROS), such as singlet oxygen $\left({ }^{1} \mathrm{O}_{2}\right)$, super oxide $\left(\cdot \mathrm{O}_{2}^{-}\right)$and $\cdot \mathrm{OH}$. Therefore, ${ }^{3} \mathrm{COM}^{*}$ plays a critical role in ROS formation and pollutant attenuation (Paul Hansard et al., 2010; Szymczak and Waite, 1988; Zhang et al., 2014; Rosario-Ortiz and Canonica, 2016; Sharpless, 2012; Haag and Gassman, 1984; Zhou et al., 2019). Aromatic ketones (Canonica et al., 2006; Marciniak et al., 1993), benzophenone (Encinas et al., 1985) and phenanthrene (Wawzonek and Laitinen, 1942) have been identified as the precursors of ${ }^{3} \mathrm{COM}^{*}$. Chemical probes, such as 2,4,6-trimethylphenol (TMP) and sorbic acid (SA), are applicable to evaluate the yield of ${ }^{3} \mathrm{COM}^{*}$ (Zhou et al., 2019; Moor et al., 2019; Chen et al., 2021). Compared with ${ }^{1} \mathrm{COM}^{*}$, the characteristics of ${ }^{3} \mathrm{COM}^{*}$ are a lower formation rate $(15 \sim 100$ times slower than ${ }^{1} \mathrm{COM}^{*}$ ), lower quenching rate (20 000 times lower than $\left.{ }^{1} \mathrm{COM}^{*}\right)$ and higher steady-state concentration $(200 \sim 1300$ times higher than $\left.{ }^{1} \mathrm{COM}^{*}\right)$ (McNeill and Canonica, 2016). Therefore, the formation rate constant of ${ }^{3} \mathrm{COM}^{*}$ is considered as the tracer for evaluating the photochemical reactivity. Considering the potential effect of ROS on aerosol aging and air quality, it is necessary to clarify the path and mechanism of COM-generating ROS.

Photodegradation may dominate the chemical component of COM and aerosol aging. In order to illustrate the characteristic and mechanism of COM photodegradation and the effect of COM photodegradation on aerosol aging, we simulate the process of COM photodegradation and COM-generating ROS in the laboratory. The objectives of the study are (1) to clarify the change of carbon content during the COM photodegradation process, (2) to explore the effect of pho- todegradation on fluorophores and optical properties, and (3) to investigate the effect of COM photodegradation on photochemical reactivity (photochemical reactivity is evaluated by ${ }^{3} \mathrm{COM}^{*}$ and ${ }^{1} \mathrm{O}_{2}$ ).

\section{Experimental section}

\subsection{Sample collection}

A total of 16 samples were collected (Table S1 in the Supplement). The ambient PM samples were collected in Shaanxi University of Science and Technology, Xi'an, Shaanxi Province $\left(34^{\circ} 22^{\prime} 35.07^{\prime \prime} \mathrm{N}, 108^{\circ} 58^{\prime} 34.58^{\prime \prime} \mathrm{E}\right.$; the height of the sampling site was about $30 \mathrm{~m}$ ). The ambient PM samples were collected on quartz fiber filter (Pall life sciences, America) by an intelligent large-flow sampler (Xintuo XT-1025, China) with a sampling time of $23 \mathrm{~h} 30 \mathrm{~min}$ and a sampling flow rate of $1000 \mathrm{Lmin}^{-1}$. The ambient PM samples were stored in the refrigerator at $-20^{\circ} \mathrm{C}$ prior to use.

The POA samples were collected by a combustion chamber (Fig. S1 in the Supplement). The main ways of heating and cooking were straw and coal burning in rural China. Therefore, wheat-straw-, corn-straw-, rice-straw- and woodburning samples were collected. The POA samples were stored in the refrigerator at $-20^{\circ} \mathrm{C}$ prior to use.

\subsection{Photodegradation experiment}

A quartz reactor was designed for the photodegradation experiment (schematic diagrams of the photochemical devices were shown in Fig. S2; details of the reactor have been described in previous study; Chen et al., 2021). The photodegradation times were $0,2,6,12,24 \mathrm{~h}, 3$ and $7 \mathrm{~d}$, and a series of the photodegraded samples were collected.

\subsection{Carbon content measurement}

Water-soluble organic matter (WSOM) was extracted from the original and photodegraded samples by sonication in ultrapure water ( $>18.2 \mathrm{M} \Omega \mathrm{cm}$, Hitech, China) and filtered through a $0.45 \mu \mathrm{m}$ filter (Jinteng, China). Then residual organic matter was further extracted in methanol (HPLC Grade, Fisher Chemical, America) and filtered through a $0.45 \mu \mathrm{m}$ filter to obtain methanol-soluble organic matter (MSOM). The background was obtained with the same method.

The measurement method of carbon content has been described previously (Mu et al., 2019). Briefly, $100 \mu \mathrm{L}$ extract was injected on the baked quartz filter. The wet filter was dried out by a rotary evaporator. Then the dried filter was analyzed by the organic carbon/element carbon (OC/EC) online analyzer (Model 4, Sunset, America) with the approach of NIOSH 870 protocol (Karanasiou et al., 2015). OC was measured in the absence of oxygen. An oven in the instrument was filled with helium. Temperature was risen and the 
different phases were at a selected temperature $\left(\mathrm{OC} 1-310^{\circ} \mathrm{C}\right.$, $\left.\mathrm{OC} 2-472^{\circ} \mathrm{C}, \mathrm{OC} 3-615^{\circ} \mathrm{C}, \mathrm{OC} 4-850^{\circ} \mathrm{C}\right)$. EC was measured in the presence of oxygen. The oven in the instrument was filled with a helium/oxygen gas mixture $\left(\mathrm{He} / \mathrm{O}_{2}=9 / 1 v / v\right)$. The different phases were also at a selected temperature $\left(\mathrm{EC} 1-550^{\circ} \mathrm{C}, \mathrm{EC} 2-625^{\circ} \mathrm{C}, \mathrm{EC} 3-700^{\circ} \mathrm{C}, \mathrm{EC} 4-775^{\circ} \mathrm{C}, \mathrm{EC} 5-\right.$ $850{ }^{\circ} \mathrm{C}, \mathrm{EC} 6-870^{\circ} \mathrm{C}$ ). The products in the heating process were further oxidized to $\mathrm{CO}_{2}$. The carbon content was obtained through the measurement of $\mathrm{CO}_{2}$. Six parallel samples were analyzed, and the uncertainty of the method was $<3.7 \%$ (1 standard deviation).

\subsection{Optical analysis}

The light absorption and Excitation Emission Matrix (EEM) spectra of WSOM and MSOM were measured by an Aqualog fluorescence spectrophotometer (Horiba Scientific, America). The range of excitation wavelength was $200-600 \mathrm{~nm}$ with an interval of $5 \mathrm{~nm}$. The range of emission wavelength was $250-800 \mathrm{~nm}$. The integration time was $0.5 \mathrm{~s}$. The absorption was also recorded in the wavelength range of 200$600 \mathrm{~nm}$. The background of water and methanol were measured using the same method and the value of background was subtracted. The extracts were diluted to reduce internal filtration effect (the concentrations and dilution factors were shown in Table S2).

The EEM data were analyzed by parallel factor analysis model (PARAFAC). The model referred to the previous papers (Murphy et al., 2013; Chen et al., 2016a; Chen et al., 2016b). WSOM and MSOM (111 samples) were combined in the dataset to build the PARAFAC model. According to the EEM characteristics and the residual error variation trend of the two-component to seven-component PARAFAC models, four components were selected (error analysis of the model is shown in Fig. S4).

\subsection{Triplet-state generation experiment}

${ }^{3} \mathrm{COM}^{*}$ is a short-lived reactive intermediate and has an important impact on photochemical process in aerosol (Kaur and Anastasio, 2018). Therefore, the difference in generation ability of ${ }^{3} \mathrm{COM}^{*}$ before and after photodegradation was studied. Only WSOM was used in the triplet-state generation experiment. The samples with a photodegradation time of 0 and $7 \mathrm{~d}$ were defined as the original and photolyzed samples, respectively. A capsule (Fig. S2c) was designed for the triplet-state experiment. TMP was the capturing agent for ${ }^{3} \mathrm{COM}^{*}$. A total of $60 \mu \mathrm{L}$ of WSOM extract (carbon content in the triplet-state generation experiment was shown in Table S3) and $60 \mu \mathrm{L}$ of TMP solution $\left(c_{\mathrm{TMP}}=20 \mu \mathrm{M}\right.$, Aladdin, China) were mixed in the capsule. The capsule was placed in the reactor (Fig. S2a). The times of optical excitation were 0 , $5,10,15,30,45,60$ and $90 \mathrm{~min}$. Then $90 \mu \mathrm{L}$ of mixture was taken out from the capsule at different time points. A total of $30 \mu \mathrm{L}$ of phenol solution $\left(c_{\text {phenol }}=50 \mu \mathrm{M}\right.$, Aladdin, China) was added into the mixture (phenol was the interior label for TMP quantification).

TMP was measured by liquid chromatography (LC). The method was as follows: a C18 column (Xuanmei, China) was used in the experiment. The mobile phase was a mixture of acetonitrile and water (acetonitrile/water $=1 / 1, v / v$ ). The flow rate was $1 \mathrm{~mL} \mathrm{~min}^{-1}$. The UV absorption spectra was measured using a UV detector with the wavelength of $210 \mathrm{~nm}$. The retention time was $14.5 \mathrm{~min}$. Previous studies have reported that TMP consumption conformed to first-order kinetics (Kaur and Anastasio, 2018; RichardsHenderson et al., 2015). The curvy fitting was performed by exponential model using the TMP concentration $\left(c_{\mathrm{TMP}} / \mu \mathrm{M}\right)$, the optical excitation time $(t / \mathrm{min})$ and triplet-state generation rate constant $\left(k_{\mathrm{TMP}} / \mathrm{min}^{-1}\right)$ :

$c_{\mathrm{TMP}}=a \cdot e^{-t \times k_{\mathrm{TMP}}}$.

\subsection{Singlet-oxygen generation experiment}

The effect of COM photodegradation on singlet oxygen was studied. A capsule was designed for ${ }^{1} \mathrm{O}_{2}$ generation experiment (Fig. S2b). The samples with photodegradation times of 0 and $7 \mathrm{~d}$ were defined as the original and photolyzed samples, respectively. Only WSOM of original and photolyzed samples was used in the experiment. 4-Hydroxy-2, 2, 6, 6-tetramethylpiperidine (TEMP, $c_{\text {TEMP }}=240 \mathrm{mM}$, Aladdin, China) was the capturing agent for ${ }^{1} \mathrm{O}_{2}$, and ${ }^{1} \mathrm{O}_{2}$ was measured by Electron Paramagnetic Resonance (EPR) spectrometer (MS5000, Freiberg, Germany). SA $\left(c_{\mathrm{SA}}=133.3 \mu \mathrm{M}\right.$, Aladdin, China) was the quenching agent for ${ }^{3} \mathrm{COM}^{*}$. The method was as follows. (1) ${ }^{1} \mathrm{O}_{2}$ was measured before optical excitation. A total of $40 \mu \mathrm{L}$ WSOM, $40 \mu \mathrm{L}$ TEMP and $40 \mu \mathrm{L}$ ultra-pure water were mixed in the capsule. Following this, $50 \mu \mathrm{L}$ of mixture was taken out by capillary for EPR analysis; (2) ${ }^{1} \mathrm{O}_{2}$ was measured for $60 \mathrm{~min}$ in the dark. A total of $40 \mu \mathrm{L}$ WSOM, $40 \mu \mathrm{L}$ TEMP and $40 \mu \mathrm{L}$ ultra-pure water were mixed in the capsule. The capsule was placed in the reactor for $60 \mathrm{~min}$ without illumination. Following this, $50 \mu \mathrm{L}$ of mixture was taken out and analyzed by EPR; (3) ${ }^{1} \mathrm{O}_{2}$ was measured in $60 \mathrm{~min}$ of optical excitation. A total of $40 \mu \mathrm{L}$ WSOM, $40 \mu \mathrm{L}$ TEMP and $40 \mu \mathrm{L}$ ultra-pure water were mixed in the capsule. The mixture was illuminated in the reactor for $60 \mathrm{~min}$. Following this, $50 \mu \mathrm{L}$ mixture was analyzed by EPR; (4) ${ }^{3} \mathrm{COM}^{*}$ was quenched and ${ }^{1} \mathrm{O}_{2}$ was measured in $60 \mathrm{~min}$ of optical excitation. A total of $40 \mu \mathrm{L}$ WSOM, $40 \mu \mathrm{L}$ TEMP and $40 \mu \mathrm{L}$ SA solution were mixed in capsule. The mixture was illuminated in the reactor for $60 \mathrm{~min}$. Following this, $50 \mu \mathrm{L}$ mixture was analyzed by EPR. 
(a) POA
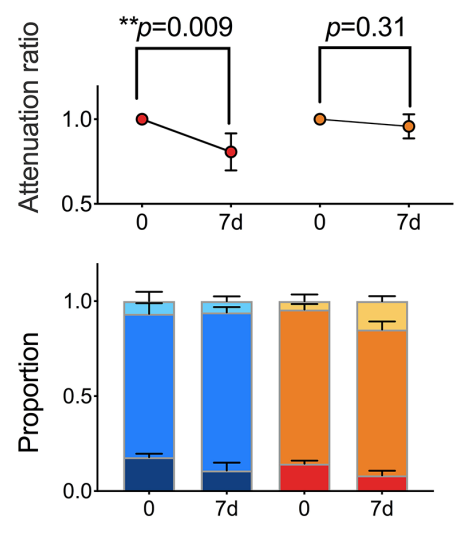

(b) Ambient PM
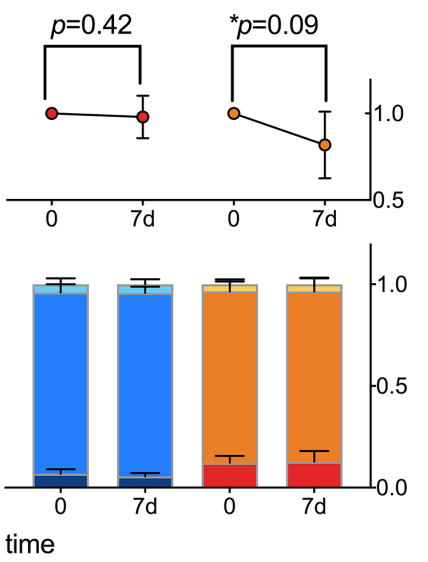
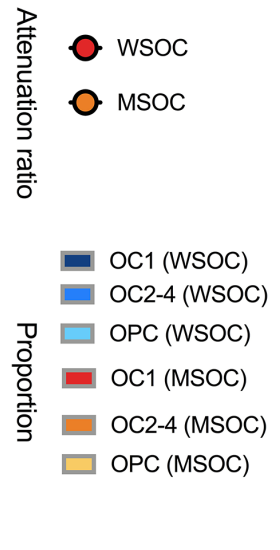

Figure 1. Changes in carbon content before and after photodegradation. The $p$ value is the probability that two sets of data have the same level (two-tailed test). ${ }^{*}$ and ${ }^{* *}$ The significant difference at the 0.1 and 0.01 levels, respectively.

\section{Results and discussion}

\subsection{Effect of COM photodegradation on carbon content}

Figure 1 exhibits the changes in carbon content before and after COM photodegradation. In POA (Fig. 1a), water-soluble and methanol-soluble organic carbon (WSOC and MSOC) decrease by $22.1 \%$ and $3.5 \%$, respectively. The results suggest that WSOC is more easily photodegraded than MSOC in POA. In WSOC of POA, the proportion of OC1 $(\mathrm{OC} 1$ and OC2-4 are the different stages in the process of thermaloptical analysis) decreases significantly and $\mathrm{OC} 1$ was the major loss of OC. OC1 is characterized by small molecular weight and high volatility (Karanasiou et al., 2015). Therefore, $\mathrm{OC}$ with the characteristics of small molecular weight and high volatility tends to be photodegraded. In MSOC of POA, the proportion of OPC in MSOC shows an increasing trend (an average increase of 2.4 times) and the proportion of $\mathrm{OC} 1$ decreases significantly. There is a process through which $\mathrm{OC} 1$ is translated into pyrolysis carbon (OPC). Pyrolysis carbon is identified as an oxygen-containing organic substance. Thus, the increase in oxygen-containing organic matter is caused by the photo-inducing oxidation reaction.

In ambient PM (Fig. 1b), WSOC is nearly unchanged and MSOC decreases by $18.2 \%$, which is in contrast to POA. POA is fresh, but ambient PM has undergone long-term aerosol aging. The results reflect that $\mathrm{OM}$ has been photodegraded adequately following the photodegradation and mineralization in WSOM of ambient PM. However, MSOC with high molecular weight could not be photodegraded adequately and thereby continues to be photodegraded in the laboratory. The proportions of OC1, OC2-4 and OPC are relatively stable in ambient PM and the characteristic is also in contrast to POA. The result indicates that the decreases in the proportions of the different stages are similar. The OM with different molecular weights may have similar abilities of photodegradation in ambient PM, and the molecular weight of $\mathrm{OM}$ is nearly unchanged following photodegradation in ambient PM.

\subsection{Effect of COM photodegradation on optical properties}

As shown in Fig. 2, both the absorption coefficient and total fluorescence volume (TFV, RU-nm ${ }^{2} \mathrm{~m}^{-3}$ ) significantly decrease following photodegradation, which suggests that COM is photo-bleaching (Aiona et al., 2018; Duarte et al., 2005; Liu et al., 2016). The first-order decay model is used to fit the attenuations of fluorescence intensity and absorption coefficient. The absorption coefficient and TFV decrease by $32.0 \%$ and $71.4 \%$ on average, respectively. However, as shown in Fig. 3, fluorescence intensities increase and decrease in different regions of EEMs (Aiona et al., 2018; Timko et al., 2015).

In POA (Fig. 2b), TFV decreases by $74.8 \%$ on average, and the exponential curve method is used to analyze the attenuation of fluorescence intensity. The attenuations of TFV are significant similarities between WSOM and MSOM. However, wood-burning samples are distinct from other POA samples: TFV of wood-burning COM only decreases by $9.0 \%$, and the fluorescence volume of MSOM of woodburning samples remains almost unchanged (Fig. S7). There are two main reasons for this. On the one hand, methanolsoluble secondary OM is generated only in small amounts in wood-burning samples (Zhong and Jang, 2014). On the other hand, methanol-soluble wood-burning COM is difficult to photodegrade. In addition, photodegradation of fluorophores also depends on the photochemical environment, such as solution pH (Aiona et al., 2018), salinity (Xu et al., 

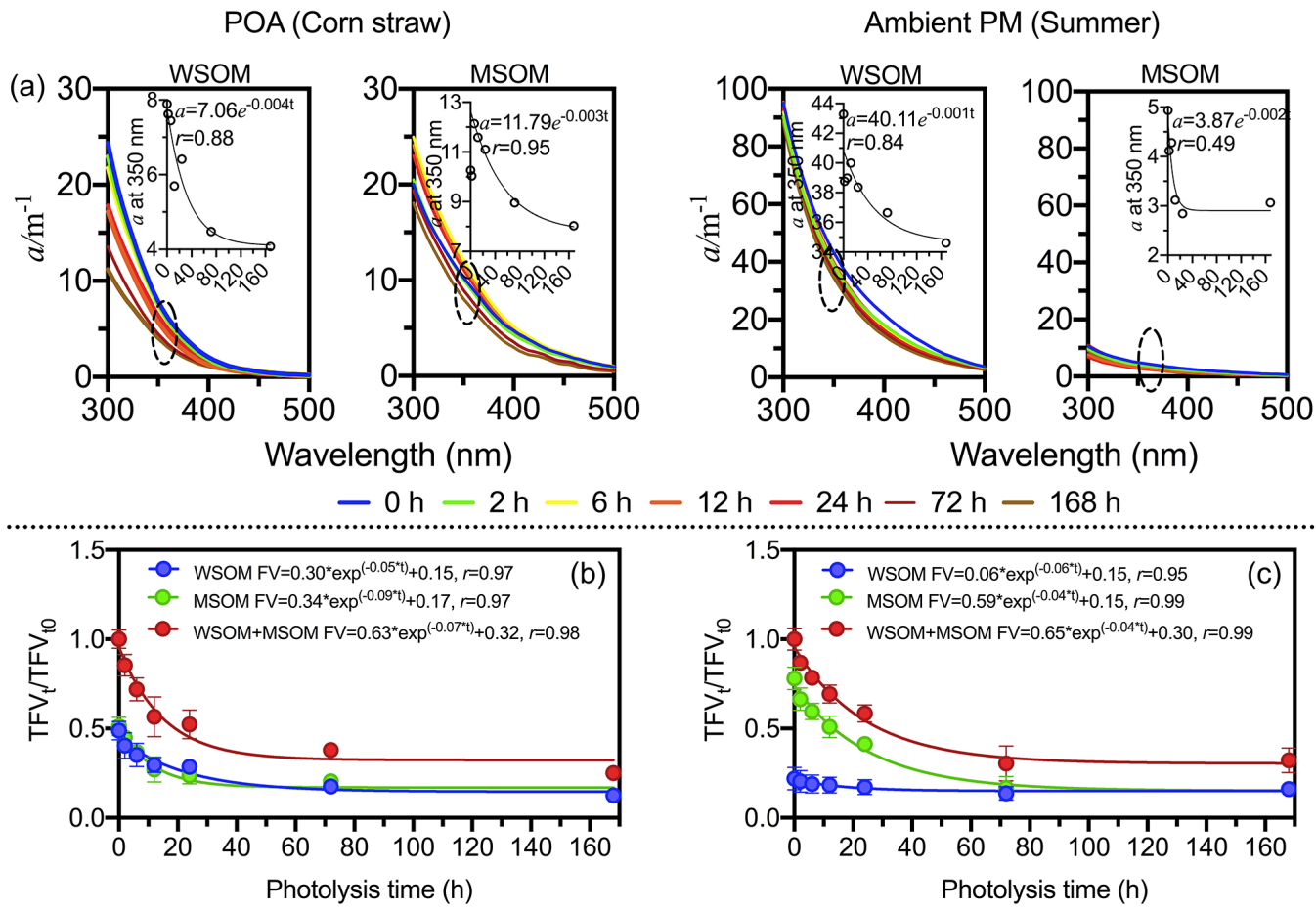

Figure 2. Changes in absorption coefficient and fluorescence volume in the photodegradation process. (a) Absorption coefficient. The scatterplot shows the absorption coefficient at $350 \mathrm{~nm}$. Panels (b) and (c) show the attenuation curve of fluorescence volume in POA (except for the wood sample) and ambient PM, respectively.

2020) and temperature (Yang et al., 2021). Therefore, we suppose that photodegradation of wood-burning COM may largely depend on photodegradation environment.

The attenuation rate constant of TFV in ambient PM $(k=$ $\left.0.04 \mathrm{~h}^{-1}\right)$ is lower than that in POA $\left(k=0.07 \mathrm{~h}^{-1}\right)$. In ambient PM (Fig. 2c), TFV decreases by $79.4 \%$ in MSOM but decreases by $26.7 \%$ in WSOM. The attenuation of TFV and carbon content are identical. The results suggest that MSOM is more easily photodegraded than WSOM in ambient PM. It is worth noting that $72 \mathrm{~h}$ could be considered as the end point of aerosol photo-aging because TFV maintains a constant value after $72 \mathrm{~h}$ both in POA and ambient PM.

Photodegradation causes the decomposition and transformation of fluorophores (Wong et al., 2015). Previous studies have analyzed the water-soluble and methanol-soluble fluorophores separately (J. Tang et al., 2020). However, based on the Chen's studies $(2020 ; 2016 b)$, water-soluble and methanol-soluble samples were combined to build the PARAFAC model to illustrate the distribution of fluorophores in WSOM and MSOM. Chen's studies (2020; 2016b) have also revealed that solvent had no significant effect on the EEMs of complex mixtures in aerosol. As shown in Fig. 3a, four fluorophores are identified. The fluorescence peaks of $\mathrm{C} 1$ and $\mathrm{C} 2$ appear at $(\mathrm{Ex} . / \mathrm{Em} .=224 / 434 \mathrm{~nm})$ and (Ex./Em. $=245 / 402 \mathrm{~nm}$ ). The peaks are similar to high- and low-oxidation HULIS, respectively (Chen et al., 2016b; Birdwell and Engel, 2010). The peaks of $\mathrm{C} 3$ and $\mathrm{C} 4$ appear at $($ Ex. $/$ Em. $=220 / 354 \mathrm{~nm})$ and $($ Ex. $/$ Em. $=277 / 329 \mathrm{~nm})$, and these two fluorophores are protein-like organic matter (PLOM-1 and PLOM-2) (Sierra et al., 2005; Huguet et al., 2009; Chen et al., 2016a and 2016b; Coble, 2007; Fellman et al., 2009).

The content of fluorophores changes significantly in the photodegradation process. In WSOM of POA (Fig. 3b), the relative content of high-oxidation HULIS (C1) increases by $63.0 \%$ and the relative content of low-oxidation HULIS (C2) decreases by $88.0 \%$. Changes in proportion indicate that low-oxidation HULIS (C2) may be converted into highoxidation HULIS (C1) due to photooxidation (S. S. Tang et al., 2020; Chen et al., 2020). PLOM (C3 and C4) decreases $19.7 \%$, and the result indicates that PLOM (C3 and C4) can be photodegraded. In MSOM of POA, no regularity is found in low-oxidation HULIS (C2) and PLOM (C3 and C4). The content of high-oxidation HULIS (C1) increases by $17.5 \%$, which is attributed to a photo-inducing secondary reaction.

In WSOM of ambient PM, the content of high-oxidation HULIS (C1) multiplied 6.9 times and the low-oxidation HULIS (C2) decreased by $40.2 \%$. The variation is similar to POA. Thus, high-oxidation HULIS could be used to trace the degree of aerosol photo-aging. The contents of PLOM (C3 and C4) in ambient PM (19.4\%) (Fig. 3c) are significantly lower than that in POA (43.3\%). In MSOM of ambient PM, the relative content of high-oxidation HULIS (C1) 
(a)
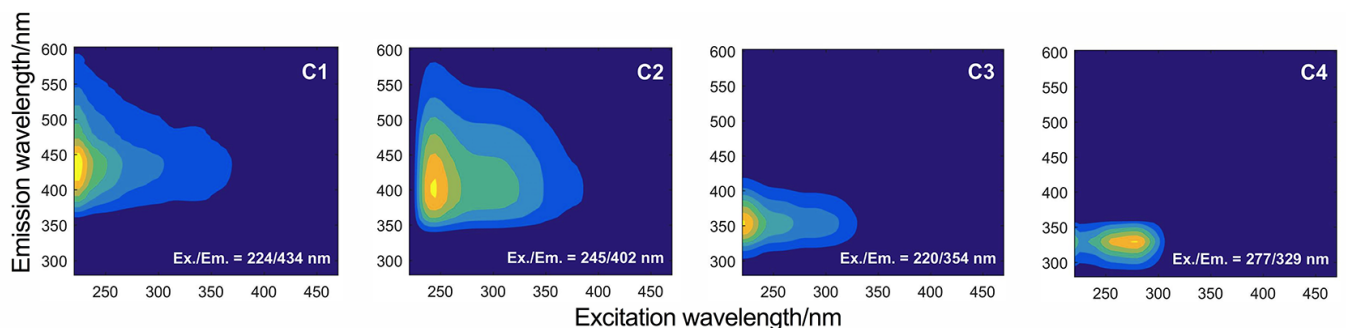

(i) Wheat Straw

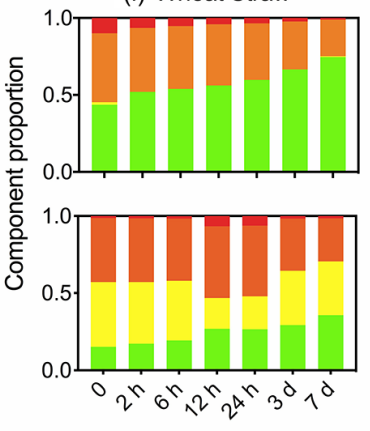

(ii) Cron Straw

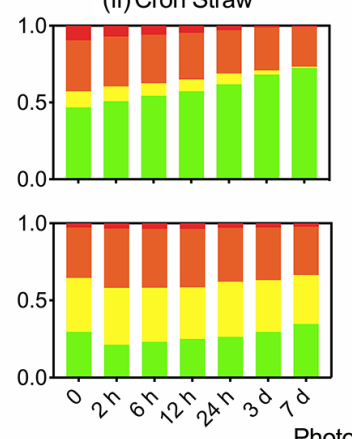

(iiii) Rice Straw

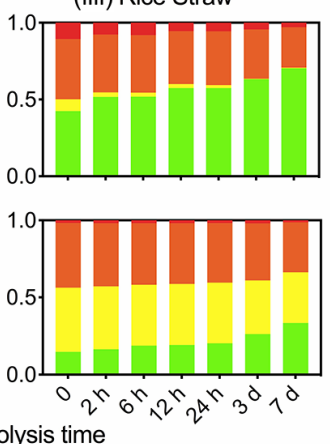

(iv) Wood

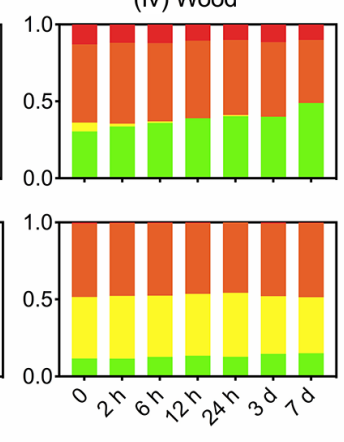

C1

$\mathrm{C} 2$

WSOM

(b)

(v) Spring

(vi) Winter

Photolysis time
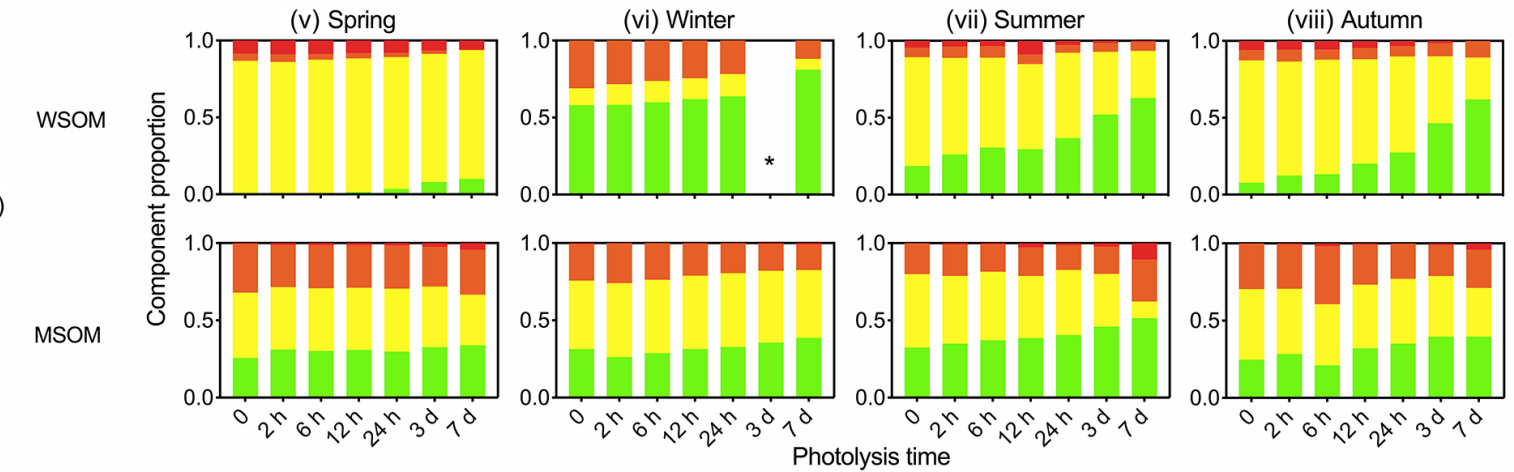

Figure 3. (a) EEM spectra of fluorophores. (b) Changes in proportion of fluorophores in POA. (c) Changes in proportion of fluorophores in ambient PM. * The data of $3 \mathrm{~d}$ photolysis of water-soluble fluorophores in winter are unavailable.

increases by $43.5 \%$ and no regularity of variation is found in low-oxidation HULIS (C2) and PLOM (C3 and C4).

\subsection{Effect of COM photodegradation on aerosol photochemical reactivity}

Photodegradation has a significant effect on photochemical reactivity of COM in aerosol. The photochemical activity is quantitatively analyzed by the yield of ${ }^{3} \mathrm{COM}^{*}$ and ${ }^{1} \mathrm{O}_{2}$. Only WSOM of original and photolyzed samples is used in the triplet-state experiment (photodegradation time of original samples is 0 , photodegradation time of photolyzed samples is $7 \mathrm{~d}$; details of samples are described in Sect. 2.2). Figure 4 shows the variation of triplet-state generation before and after the photodegradation (consumption curves of TMP are shown in Fig. S8). In ambient PM, compared with original samples, the consumption rate constant of TMP $\left(k_{\mathrm{TMP}}\right)$ decreases by $11 \%$ on average in photolyzed samples, while statistical analysis shows that the changes are not obvious ( $p=0.38$, two-tailed test). On the contrary, in POA $k_{\text {TMP }}$ increases $75 \%$ on average after photodegradation ( $p=0.07$, two-tailed test). That triplet-state generation remains unchanged or increases in different aerosols following photodegradation is unexpected and can be explained by a recent study (Chen et al., 2021). On the one hand, only a small proportion of water-soluble OM and fluorophores could generate a triplet state in aerosol. Therefore, the ability of tripletstate generation could not be evaluated by only fluorescence intensity. On the other hand, we use a high concentration of TMP; in this case, TMP mainly captures high-energy triplet states (Rosado-Lausell et al., 2013; Chen et al., 2021). Thus, COM, which could generate a high-energy triplet state, may not be photodegraded in ambient PM.

The effect of COM photodegradation on singlet oxygen is studied. COM can generate triplet state and further generate singlet oxygen (McNeill and Canonica, 2016). WSOM of original and photolyzed samples is used in singlet oxygen experiment (EPR spectra of all samples is shown in Figs. S9 

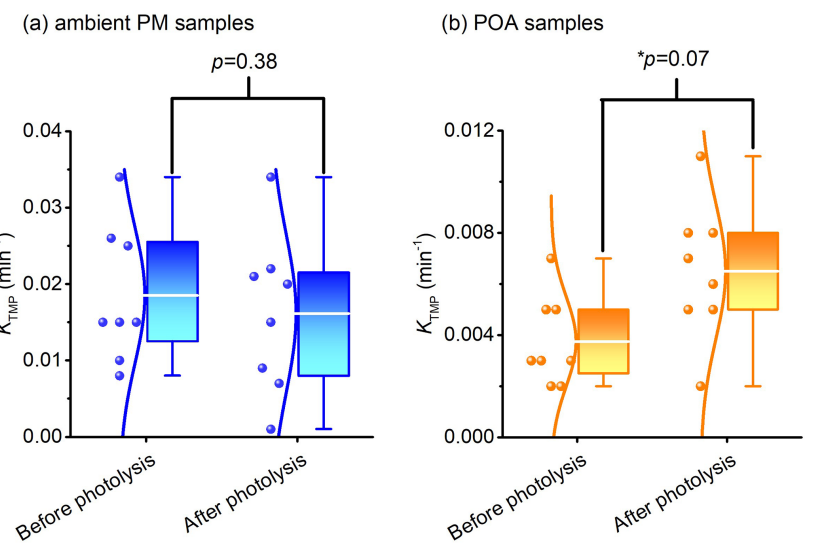

Figure 4. Changes in the triplet-state generation: (a) ambient PM and (b) POA. The lines from bottom to top in the box plots show the minimum, first quartile, the average value (white lines), third quartile, and maximum, respectively. The $p$ value is the probability that two sets of data have the same level (two-tailed test). ${ }^{*} \mathrm{~A}$ significant difference is present at the 0.1 level.

and S10). As shown in Fig. 5, a decrease in the yield of ${ }^{1} \mathrm{O}_{2}$ reveals the inhibiting effect of COM photodegradation on photochemical activity both in ambient PM and POA. In POA, as shown in Fig. 5a, (i) before optical excitation there is little ${ }^{1} \mathrm{O}_{2}$ both in original and photolyzed samples. (ii) After 60 min of darkness, ${ }^{1} \mathrm{O}_{2}$ is generated both in original and photolyzed samples, which suggests that ${ }^{1} \mathrm{O}_{2}$ could be generated in POA without optical excitation. The content of ${ }^{1} \mathrm{O}_{2}$ in the original samples is higher than that in photolyzed samples. (iii) After 60 min of optical excitation, as expected, compared with the samples without optical excitation, the content of ${ }^{1} \mathrm{O}_{2}$ increases by 3 times in both the original and photolyzed samples. The content of ${ }^{1} \mathrm{O}_{2}$ in original samples is also higher than that in photolyzed samples ( $42.1 \%$ higher), which proves the inhibiting effect of COM photodegradation on ${ }^{1} \mathrm{O}_{2}$ generation. (iv) However, the content of ${ }^{1} \mathrm{O}_{2}$ is nearly unchanged when the triplet state is quenched by sorbic acid. Sorbic acid is a quenching agent for the high-energy triplet state (triplet energies $E_{\mathrm{T}}=239$ $247 \mathrm{~kJ} \mathrm{~mol}^{-1}$ ) (Zhou et al., 2019; Moor et al., 2019). Therefore, the low-energy ${ }^{3} \mathrm{COM}^{*}\left(E_{\mathrm{T}}<239 \mathrm{~kJ} \mathrm{~mol}^{-1}\right)$ may be the main precursor for ${ }^{1} \mathrm{O}_{2}\left(E_{\mathrm{T}}=94 \mathrm{~kJ} \mathrm{~mol}^{-1}\right)$ in POA. In addition, COM photodegradation does not change the mechanism of low-energy ${ }^{3} \mathrm{COM}^{*}$ generating ${ }^{1} \mathrm{O}_{2}$ in POA.

In ambient PM, as shown in Fig. 5b, (v) before optical excitation the content of ${ }^{1} \mathrm{O}_{2}$ is very low in the original and photolyzed samples, which is similar to POA. (vi) Compared with (v), the content of ${ }^{1} \mathrm{O}_{2}$ is almost unchanged after $60 \mathrm{~min}$ of darkness, which is different from POA. The result suggests that ${ }^{1} \mathrm{O}_{2}$ could not be generated in ambient PM without optical excitation. (vii) After $60 \mathrm{~min}$ of optical excitation, the content of ${ }^{1} \mathrm{O}_{2}$ increases significantly and the content of ${ }^{1} \mathrm{O}_{2}$ in original samples is higher than that in photolyzed samples
( $41.0 \%$ higher). (viii) When the triplet state is quenched by sorbic acid, ${ }^{1} \mathrm{O}_{2}$ is not generated. The result suggests that the precursor of ${ }^{1} \mathrm{O}_{2}$ is quenched and that ${ }^{1} \mathrm{O}_{2}$ is mainly generated by high-energy ${ }^{3} \mathrm{COM}^{*}$ in ambient $\mathrm{PM}$. The quenching effects of sorbic acid on the triplet state in POA and ambient PM are different because of the different energy of the triplet state. COM with the ability of generating high-energy triplet state could be photodegraded, which directly leads to the decrease in ${ }^{1} \mathrm{O}_{2}$ in ambient PM.

\section{Implications}

We made a comprehensive study of the characteristics and mechanisms of COM photodegradation and illustrated the effect of COM photodegradation on optical properties, chemical components, and photochemical reactivity. COM photodegradation could result in a decrease in carbon content, the attenuation of optical properties, and a change in the fluorescent component. We also proposed that COM photodegradation should be evaluated from three aspects for further study. (1) The impact of COM photodegradation on carbon content was unclear. Previous studies have revealed that WSOC of river-dissolved organic matter (DOM) did not change significantly (Gonsior et al., 2009) and $0.2 \%$ of DOC was mineralized (Tranvik and Kokalj, 1998). However, the observation in the study suggested that the changes in carbon content were different in aerosols, which could be attributed to the differences in original components. (2) Attenuation in optical properties was significant. Absorption coefficient and fluorescence intensity could be thought of as a tracer for molecular weight during the photodegradation process (Stewart and Wetzel, 1980). The characteristic could be suitable for exploring the impact of photodegradation on COM components. (3) Photodegradation may dominate the fluorophore components (Aiona et al., 2018; Timko et al., 2015). High-molecular-weight COM could be decomposed into low-molecular-weight COM during the photodegradation process. The conversion of low-oxidation HULIS to high-oxidation HULIS was observed. Changes in COM may reveal the oxidation degree of organic substances. Therefore, we suggested that the optical parameters and oxidation degrees of organic matter should be used for characterizing the aerosol photo-aging process (Maizel et al., 2017).

Photodegradation not only changed the properties and components of COM but also changed their photochemical reactivity, which had a further potential impact on the aerosol fate (McNight et al., 2001; Zepp et al., 1985). Photochemical reactivity was quantified by the yield of triplet state and ${ }^{1} \mathrm{O}_{2}$ in our study. However, two different methods gave two different results. Photodegradation had a significant inhibiting effect on the yield of ${ }^{1} \mathrm{O}_{2}$ in aerosol (Latch and McNeill, 2006; Chen et al., 2018). We insisted that aerosol aging would be changed due to the yield of ${ }^{1} \mathrm{O}_{2}$ being changed. Changes in the generation of triplet state were different in ambient PM 

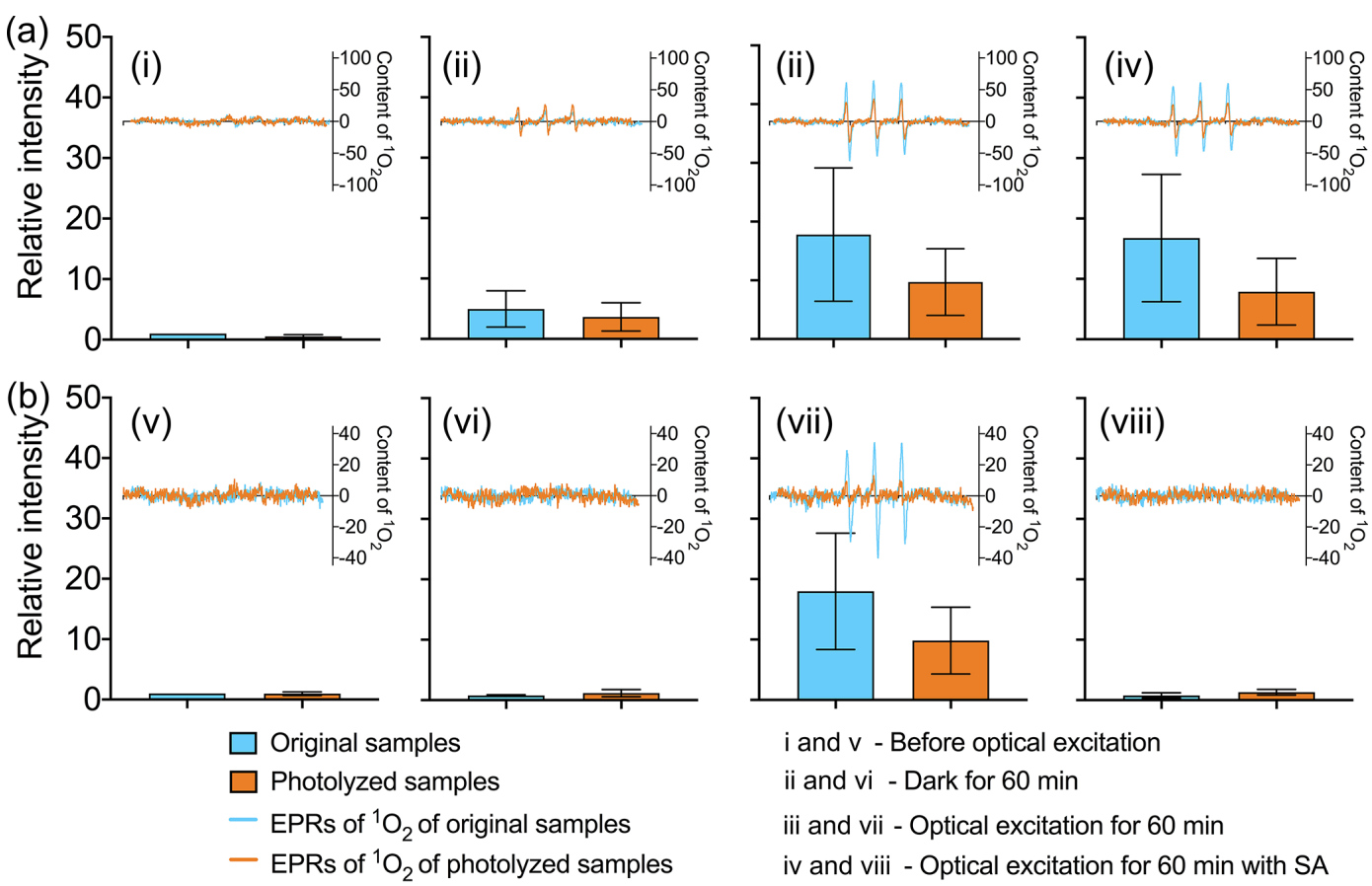

Figure 5. Changes in COM generating ${ }^{1} \mathrm{O}_{2}$ before and after photodegradation: (a) POA and (b) ambient POA.

and POA. There were two reasons for this. On the one hand, only a small amount of $\mathrm{COM}$ was a precursor of ${ }^{3} \mathrm{COM}^{*}$ in aerosol. On the other hand, the energy of capturing agent was closely related to ${ }^{3} \mathrm{COM}^{*}$ quantification. ${ }^{3} \mathrm{COM}^{*}$ could not be captured completely by TMP. Other capturing agents may lead to different results. Thus, ${ }^{3} \mathrm{COM}^{*}$ could not properly illustrate photodegradation. COM photodegradation could play an important role in the content of ROS, and ROS could affect the COM photooxidation (Claeys et al., 2004). Given the results, the interaction effect in aerosol should be further studied.

In summary, atmospheric photochemistry had a remarkable impact on aerosol aging. Prediction of atmospheric lifetime and improvement of air quality were strongly associated with photochemistry. We proved that carbon content, absorption coefficient, fluorescence intensity, and photochemical reactivity were useful to reflect the photodegradation process and aerosol fate. In addition, there were different mechanisms of COM photodegradation affecting chemical reactivity in different aerosols, and thus the mechanisms deserve to be investigated further.

Data availability. All data that support the findings of this study are available in this article and its Supplement or from the corresponding author on request.

Supplement. Additional details, including Tables S1-S5, Figs. S1S10, and calculation of optical characteristics of WSOM and
MSOM, are contained in the Supplement. The supplement related to this article is available online at: https://doi.org/10.5194/acp-2111581-2021-supplement.

Author contributions. QC and ZM designed the experiments and data analysis. ZM and LZ performed sample collection. ZM performed the photochemical experiment. ZM and DG performed the OC/EC analysis and optical analysis. HL performed the EPR analysis. QC prepared the paper with the contributions from all coauthors.

Competing interests. The authors declare that they have no conflict of interest.

Disclaimer. Publisher's note: Copernicus Publications remains neutral with regard to jurisdictional claims in published maps and institutional affiliations.

Acknowledgements. We thank the National Natural Resources Foundation for its financial support.

Financial support. This research has been supported by the National Natural Science Foundation of China (grant no. 41877354) and the Youth Science and Technology Nova Program of Shaanxi Province (2021KJXX-36). 
Review statement. This paper was edited by Sergey A. Nizkorodov and reviewed by two anonymous referees.

\section{References}

Aiona, P. K., Luek, J. L., Timko, S. A., Powers, L. C., Gonsior, M., and Nizkorodov, S. A.: Effect of Photolysis on Absorption and Fluorescence Spectra of Light-Absorbing Secondary Organic Aerosols, ACS Earth Space Chem., 2, 235-245, https://doi.org/10.1021/acsearthspacechem.7b00153, 2018.

Altieri, K. E., Carlton, A. G., Lim, H. J., Turpin, B. J., and Seitzinger, S. P.: Evidence for oligomer formation in clouds: Reactions of isoprene oxidation products, Environ. Sci. Technol., 40, 4956-4960, https://doi.org/10.1021/es052170n, 2006.

Altieri, K. E., Seitzinger, S. P., Carlton, A. G., Turpin, B. J., Klein, G. C., and Marshall, A. G.: Oligomers formed through in-cloud methylglyoxal reactions: Chemical composition, properties, and mechanisms investigated by ultra-high resolution FT-ICR mass spectrometry, Atmos. Environ., 42, 1476-1490, https://doi.org/10.1016/j.atmosenv.2007.11.015, 2008.

Andreae, M. O. and Gelencsér, A.: Black carbon or brown carbon? The nature of light-absorbing carbonaceous aerosols, Atmos. Chem. Phys., 6, 3131-3148, https://doi.org/10.5194/acp-63131-2006, 2006.

Atkinson, R., Baulch, D. L., Cox, R. A., Crowley, J. N., Hampson, R. F., Hynes, R. G., Jenkin, M. E., Rossi, M. J., Troe, J., and IUPAC Subcommittee: Evaluated kinetic and photochemical data for atmospheric chemistry: Volume II - gas phase reactions of organic species, Atmos. Chem. Phys., 6, 3625-4055, https://doi.org/10.5194/acp-6-3625-2006, 2006.

Birdwell, J. E. and Engel, A. S.: Characterization of dissolved organic matter in cave and spring waters using UV-Vis absorbance andfluorescence spectroscopy, Org. Geochem., 41, 270-280, https://doi.org/10.1016/j.orggeochem.2009.11.002, 2010.

Budisulistiorini, S. H., Riva, M., Williams, M., Chen, J., Itoh, M., Surratt, J. D., and Kuwata, M.: Light-Absorbing Brown Carbon Aerosol Constituents from Combustion of Indonesian Peat and Biomass, Environ. Sci. Technol., 51, 4415-4423, https://doi.org/10.1021/acs.est.7b00397, 2017.

Canonica, S., Hellrung, B., Müller, P., and Wirz, J.: Aqueous Oxidation of Phenylurea Herbicides by Triplet Aromatic Ketones, Environ. Sci. Tech., 40, 6636-6641, https://doi.org/10.1021/es0611238, 2006.

Carlton, A. G., Turpin, B. J., Altieri, K. E., Seitzinger, S., Reff, A., Lim, H. J., and Ervens, B.: Atmospheric oxalic acid and SOA production from glyoxal: Results of aqueous photooxidation experiments, Atmos. Environ., 41, 7588-7602, https://doi.org/10.1016/j.atmosenv.2007.05.035, 2007.

Chen, Q., Miyazaki, Y., Kawamura, K., Matsumoto, K., Coburn, S., Volkamer, R., Iwamoto, Y., Kagami, S., Deng, Y., Ogawa, S., Ramasamy, S., Kato, S., Ida, A., Kajii, Y., and Mochida, M.: Characterization of Chromophoric WaterSoluble Organic Matter in Urban, Forest, and Marine Aerosols by HR-ToF-AMS Analysis and Excitation-Emission Matrix Spectroscopy, Environ. Sci. Technol., 50, 10351-10360, https://doi.org/10.1021/acs.est.6b01643, 2016a.
Chen, Q. C., Ikemori, F., and Mochida, M.: Light Absorption and Excitation-Emission Fluorescence of Urban Organic Aerosol Components and Their Relationship to Chemical Structure, Environ. Sci. Technol., 50, 10859-10868, https://doi.org/10.1021/acs.est.6b02541, 2016b.

Chen, Q., Li, J., Hua, X., Jiang, X., Mu, Z., Wang, M., Wang, J., Shan, M., Yang, X., Fan, X., Song, J., Wang, Y., Guan, D., and Du, L.: Identification of species and sources of atmospheric chromophores by fluorescence excitation-emission matrix with parallel factor analysis, Sci. Total Environ., 718, 137322, https://doi.org/10.1016/j.scitotenv.2020.137322, 2020.

Chen, Q., Mu, Z., Xu, L., Wang, M., Wang, J., Shan, M., Fan, X., Song, J., Wang, Y., Lin, P., and Du, L.: Triplet-state organic matter in atmospheric aerosols: Formation characteristics and potential effects on aerosol aging, Atmos. Environ., 252, 118343, https://doi.org/10.1016/j.atmosenv.2021.118343, 2021.

Chen, Y., Zhang, X., and Feng, S.: Contribution of the Excited Triplet State of Humic Acid and Superoxide Radical Anion to Generation and Elimination of Phenoxyl Radical, Environ. Sci. Technol., 52, 8283-8291, https://doi.org/10.1021/acs.est.8b00890, 2018.

Cheng, Y., He, K. B., Du, Z. Y., Engling, G., Liu, J. M., Ma, Y. L., Zheng, M., and Weber, R. J.: The characteristics of brown carbon aerosol during winter in Beijing, Atmos. Environ., 127, 355-364, https://doi.org/10.1016/j.atmosenv.2015.12.035, 2016.

Claeys, M., Graham, B., Vas, G., Wang, W., Vermeylen, R., Pashynska, V., Cafmeyer, J., Guyon, P., Andreae, M. O., Artaxo, P., and Maenhaut, W.: Formation of secondary organic aerosols through photooxidation of isoprene, Science, 303, 1173-1176, https://doi.org/10.1126/science.1092805, 2004.

Coble, P. G.: Marine optical biogeochemistry: the chemistry of ocean color, Chem. Rev., 107, 402-418, https://doi.org/10.1021/cr050350+, 2007.

Duarte, R. M. B. O., Pio, C. A., and Duarte, A. C.: Spectroscopic study of the water-soluble organic matter isolated from atmospheric aerosols collected under different atmospheric conditions, Anal. Chim. Acta, 530, 7-14, https://doi.org/10.1016/j.aca.2004.08.049, 2005.

Encinas, M. V., Lissi, E. A., and Olea, A. F.: Quenching of triplet benzophenone by vitamins $\mathrm{E}$ and $\mathrm{C}$ and by sulfur containing amino acids and peptides, Photochem. Photobiol., 42, 347-352, https://doi.org/10.1111/j.1751-1097.1985.tb01580.x, 1985.

Fellman, J. B., Miller, M. P., Cory, R. M., D’Amore, D. V., and White, D.: Characterizing Dissolved Organic Matter Using PARAFAC Modeling of Fluorescence Spectroscopy: A Comparison of Two Models, Environ. Sci. Technol., 43, 6228-6234, https://doi.org/10.1021/es900143g, 2009.

George, C., Ammann, M., D’Anna, B., Donaldson, D. J., and Nizkorodov, S. A.: Heterogeneous Photochemistry in the Atmosphere, Chem. Rev., 115, 4218-4258, https://doi.org/10.1021/cr500648z, 2015.

Gonsior, M., Peake, B. M., Cooper, W. T., Podgorski, D., D'Andrilli, J., and Cooper, W. J.: Photochemically induced changes in dissolved organic matter identified by ultrahigh resolution fourier transform ion cyclotron resonance mass spectrometry, Environ. Sci. Technol., 43, 698-703, https://doi.org/10.1021/es8022804, 2009.

Graber, E. R. and Rudich, Y.: Atmospheric HULIS: How humiclike are they? A comprehensive and critical review, Atmos. 
Chem. Phys., 6, 729-753, https://doi.org/10.5194/acp-6-7292006, 2006.

Grieshop, A. P., Donahue, N. M., and Robinson, A. L.: Laboratory investigation of photochemical oxidation of organic aerosol from wood fires 2: analysis of aerosol mass spectrometer data, Atmos. Chem. Phys., 9, 2227-2240, https://doi.org/10.5194/acp-9-22272009, 2009.

Haag, W. R. and Gassman, E.: Singlet oxygen in surface watersPart II: Quantum yields of its production by some natural humic materials as a function of wavelength, Chemosphere, 13, 641650, https://doi.org/10.1016/0045-6535(84)90200-5, 1984.

Harrison, A. W., Waterson, A. M., and De Bruyn, W. J.: Spectroscopic and Photochemical Properties of Secondary Brown Carbon from Aqueous Reactions of Methylglyoxal, ACS Earth Space Chem., 4, 762-773, https://doi.org/10.1021/acsearthspacechem.0c00061, 2020.

Haynes, J. P., Miller, K. E., and Majestic, B. J.: Investigation into Photoinduced Auto-Oxidation of Polycyclic Aromatic Hydrocarbons Resulting in Brown Carbon Production, Environ. Sci. Technol., 53, 682-691, https://doi.org/10.1021/acs.est.8b05704, 2019.

Holmes, B. J. and Petrucci, G. A.: Water-soluble oligomer formation from acid-catalyzed reactions of levoglucosan in proxies of atmospheric aqueous aerosols, Environ. Sci. Technol., 40, 49834989, https://doi.org/10.1021/es060646c, 2006.

Huguet, A., Vacher, L., Relexans, S., Saubusse, S., Froidefond, J. M., and Parlanti, E.: Properties of fluorescent dissolved organic matter inthe Gironde Estuary, Org. Geochem., 40, 706719, https://doi.org/10.1016/j.orggeochem.2009.03.002, 2009.

Jo, D. S., Park, R. J., Lee, S., Kim, S.-W., and Zhang, X.: A global simulation of brown carbon: implications for photochemistry and direct radiative effect, Atmos. Chem. Phys., 16, 3413-3432, https://doi.org/10.5194/acp-16-3413-2016, 2016.

Karanasiou, A., Minguillón, M. C., Viana, M., Alastuey, A., Putaud, J.-P., Maenhaut, W., Panteliadis, P., Močnik, G., Favez, O., and Kuhlbusch, T. A. J.: Thermal-optical analysis for the measurement of elemental carbon (EC) and organic carbon (OC) in ambient air a literature review, Atmos. Meas. Tech. Discuss., 8, 9649-9712, https://doi.org/10.5194/amtd-8-9649-2015, 2015.

Kaur, R. and Anastasio, C.: First Measurements of Organic Triplet Excited States in Atmospheric Waters, Environ. Sci. Technol., 52, 5218-5226, https://doi.org/10.1021/acs.est.7b06699, 2018.

Latch, D. E. and McNeill, K.: Microheterogeneity of singlet oxygen distributions in irradiated humic acid solutions, Science, 311, 1743-1747, https://doi.org/10.1126/science.1121636, 2006.

Lee, H. J., Laskin, A., Laskin, J., and Nizkorodov, S. A.: Excitationemission spectra and fluorescence quantum yields for fresh and aged biogenic secondary organic aerosols, Environ. Sci. Technol., 47, 5763-5770, https://doi.org/10.1021/es400644c, 2013.

Lee, H. J., Aiona, P. K., Laskin, A., Laskin, J., and Nizkorodov, S. A.: Effect of solar radiation on the optical properties and molecular composition of laboratory proxies of atmospheric brown carbon, Environ. Sci. Technol., 48, 10217-10226, https://doi.org/10.1021/es502515r, 2014.

Liu, J., Lin, P., Laskin, A., Laskin, J., Kathmann, S. M., Wise, M., Caylor, R., Imholt, F., Selimovic, V., and Shilling, J. E.: Optical properties and aging of light-absorbing secondary organic aerosol, Atmos. Chem. Phys., 16, 12815-12827, https://doi.org/10.5194/acp-16-12815-2016, 2016.

Maizel, A. C., Li, J., and Remucal, C. K.: Relationships Between Dissolved Organic Matter Composition and Photochemistry in Lakes of Diverse Trophic Status, Environ. Sci. Technol., 51, 9624-9632, https://doi.org/10.1021/acs.est.7b01270, 2017.

Mang, S. A., Henricksen, D. K., Bateman, A. P., Andersen, M. P. S., Blake, D. R., and Nizkorodov, S. A.: Contribution of Carbonyl Photochemistry to Aging of Atmospheric Secondary Organic Aerosol, J. Phys. Chem. A, 112, 8337-8344, https://doi.org/10.1021/jp804376c, 2008.

Marciniak, B., Bobrowski, K., and Hug, G. L.: Quenching of triplet states of aromatic ketones by sulfur-containing amino acids in solution. Evidence for electron transfer, J. Phys. Chem., 97, 1193711943, https://doi.org/10.1021/j100148a015, 1993.

McKnight, D. M., Boyer, E. W., Westerhoff, P. K., Doran, P. T., Kulbe, T., and Andersen, D. T.: Spectrofluorometric characterization of dissolved organic matter for indication of precursor organic material and aromaticity, Limnol. Oceanogr., 46, 38-48, https://doi.org/10.4319/lo.2001.46.1.0038, 2001.

McNeill, K. and Canonica, S.: Triplet state dissolved organic matter in aquatic photochemistry: reaction mechanisms, substrate scope, and photophysical properties, Environ. Sci.-Proc. Imp., 18, 1381-1399, https://doi.org/10.1039/c6em00408c, 2016.

Moor, K. J., Schmitt, M., Erickson, P. R., and McNeill, K.: Sorbic Acid as a Triplet Probe: Triplet Energy and Reactivity with Triplet-State Dissolved Organic Matter via ${ }^{1} \mathrm{O}_{2}$ Phosphorescence, Environ. Sci. Technol., 53, 8078-8086, https://doi.org/10.1021/acs.est.9b01787, 2019.

Mu, Z., Chen, Q. C., Wang, Y. Q., Shen, Z. X., Hua, X. Y., Zhang, Z. M., Sun, H. Y., Wang, M. M., and Zhang, L. X.: Characteristics of Carbonaceous Aerosol Pollution in $\mathrm{PM}_{2.5}$ in Xi'an, Huan Jing Ke Xue, 40, 1529-1536, https://doi.org/10.13227/j.hjkx.201807135, 2019.

Murphy, K. R., Stedmon, C. A., Graeber, D., and Bro, R.: Fluorescence spectroscopy and multi-way techniques. PARAFAC, Anal. Methods-UK, 5, 6557-6566, https://doi.org/10.1039/c3ay41160e, 2013.

Nebbioso, A. and Piccolo, A.: Molecular characterization of dissolved organic matter (DOM): a critical review, Anal. Bioanal. Chem. 405, 109-124, https://doi.org/10.1007/s00216-012-6363$2,2013$.

Paul Hansard, S., Vermilyea, A. W., and Voelker, B. M.: Measurements of superoxide radical concentration and decay kinetics in the Gulf of Alaska, Deep-Sea Res. Pt. I, 57, 1111-1119, https://doi.org/10.1016/j.dsr.2010.05.007, 2010.

Perri, M. J., Seitzinger, S., and Turpin, B. J.: Secondary organic aerosol production from aqueous photooxidation of glycolaldehyde: Laboratory experiments, Atmos. Environ., 43, 1487-1497, https://doi.org/10.1016/j.atmosenv.2008.11.037, 2009.

Richards-Henderson, N. K., Pham, A. T., Kirk, B. B., and Anastasio, C.: Secondary organic aerosol from aqueous reactions of green leaf volatiles with organic triplet excited states and singlet molecular oxygen, Environ. Sci. Technol., 49, 268-276, https://doi.org/10.1021/es503656m, 2015.

Rosado-Lausell, S. L., Wang, H. T., Gutierrez, L., RomeroMaraccini, O. C., Niu, X. Z., Gin, K. Y. H., Croue, J. P., and Nguyen, T. H.: Roles of singlet oxygen and triplet excited state of dissolved organic matter formed by different organic 
in bacteriophage MS2 inactivation, Water Res., 47, 4869-4879, https://doi.org/10.1016/j.watres.2013.05.018, 2013.

Rosario-Ortiz, F. L. and Canonica, S.: Probe Compounds to Assess the Photochemical Activity of Dissolved Organic Matter, Environ. Sci. Technol., 50, 12532-12547, https://doi.org/10.1021/acs.est.6b02776, 2016.

Saleh, R., Hennigan, C. J., McMeeking, G. R., Chuang, W. K., Robinson, E. S., Coe, H., Donahue, N. M., and Robinson, A. L.: Absorptivity of brown carbon in fresh and photo-chemically aged biomass-burning emissions, Atmos. Chem. Phys., 13, 76837693, https://doi.org/10.5194/acp-13-7683-2013, 2013.

Sharpless, C. M.: Lifetimes of Triplet Dissolved Natural Organic Matter (DOM) and the Effect of NaBH4 Reduction on Singlet Oxygen Quantum Yields: Implications for DOM Photophysics, Environ. Sci. Technol., 46, 4466-4473, https://doi.org/10.1021/es300217h, 2012.

Sierra, M. M. D., Giovanela, M., Parlanti, E., and SorianoSierra, E. J.: Fluorescence fingerprint of fulvic and humic acids from varied originsas viewed by single-scan and excitation/emission matrix techniques, Chemosphere, 58, 715-733, https://doi.org/10.1016/j.chemosphere.2004.09.038, 2005.

Stewart, A. J. and Wetzel, R. G: Fluorescence: absorbance ratios - a molecular-weight tracer of dissolved organic matter, Limnol. Oceanogr., 25, 559-564, https://doi.org/10.4319/lo.1980.25.3.0559, 1980.

Szymczak, R. and Waite, T.: Generation and decay of hydrogen peroxide in estuarine waters, Mar. Freshwater Res., 39, 289-299, https://doi.org/10.1071/MF9880289, 1988.

Tang, J., Li, J., Su, T., Han, Y., Mo, Y., Jiang, H., Cui, M., Jiang, B., Chen, Y., Tang, J., Song, J., Peng, P., and Zhang, G.: Molecular compositions and optical properties of dissolved brown carbon in biomass burning, coal combustion, and vehicle emission aerosols illuminated by excitation-emission matrix spectroscopy and Fourier transform ion cyclotron resonance mass spectrometry analysis, Atmos. Chem. Phys., 20, 2513-2532, https://doi.org/10.5194/acp-20-2513-2020, 2020.

Tang, S. S., Li, F. H., Tsona, N. T., Lu, C. Y., Wang, X. F., and Du, L.: Aqueous-Phase Photooxidation of Vanillic Acid: A Potential Source of Humic-Like Substances (HULIS), ACS Earth Space Chem., 4, 862-872, https://doi.org/10.1021/acsearthspacechem.0c00070, 2020.

Timko, S., Maydanov, A., Pittelli, S., Conte, M., Cooper, W., Koch, B., Schmitt-Kopplin, P., and Gonsior, M.: Depthdependent photodegradation of marine dissolved organic matter, Frontiers in Marine Science, 2, 66, https://doi.org/10.3389/fmars.2015.00066, 2015.

Tranvik, L. and Kokalj, S.: Decreased biodegradability of algal DOC due to interactive effects of UV radiation and humic matter, Aquat. Microb. Ecol., 14, 301-307, https://doi.org/10.3354/ame014301, 1998.

Wawzonek, S. and Laitinen, H. A.: The Reduction of Unsaturated Hydrocarbons at the Dropping Mercury Electrode. II. Aromatic Polynuclear Hydrocarbons, J. Am. Chem. Soc., 64, 2365-2368, https://doi.org/10.1021/ja01262a040, 1942.
Wenk, J., Aeschbacher, M., Salhi, E., Canonica, S., von Gunten, U., and Sander, M.: Chemical oxidation of dissolved organic matter by chlorine dioxide, chlorine, and ozone: effects on its optical and antioxidant properties, Environ. Sci. Technol., 47, 1114711156, https://doi.org/10.1021/es402516b, 2013.

Wong, J. P. S., Zhou, S. M., and Abbatt, J. P. D.: Changes in Secondary Organic Aerosol Composition and Mass due to Photolysis: Relative Humidity Dependence, J. Phys. Chem. A, 119, 4309-4316, https://doi.org/10.1021/jp506898c, 2015.

Xu, W., Gao, Q., He, C., Shi, Q., Hou, Z.-Q., and Zhao, H.-Z.: Using ESI FT-ICR MS to Characterize Dissolved Organic Matter in Salt Lakes with Different Salinity, Environ. Sci. Technol., 54, 12929 12937, https://doi.org/10.1021/acs.est.0c01681, 2020.

Yang, X. M., Yuan, J., Yue, F. J., Li, S. L., Wang, B. L., Mohinuzzaman, M., Liu, Y. J., Senesi, N., Lao, X. Y., Li, L. L., Liu, C. Q., Ellam, R. M., Vione, D., and Mostofa, K. M. G.: New insights into mechanisms of sunlight- and dark-mediated high-temperature accelerated diurnal production-degradation of fluorescent DOM in lake waters, Sci. Total Environ., 760, 14, https://doi.org/10.1016/j.scitotenv.2020.143377, 2021.

Zappoli, S., Andracchio, A., Fuzzi, S., Facchini, M. C., Gelencser, A., Kiss, G., Krivacsy, Z., Molnar, A., Meszaros, E., Hansson, H. C., Rosman, K., and Zebuhr, Y.: Inorganic, organic and macromolecular components of fine aerosol in different areas of Europe in relation to their water solubility, Atmos. Environ., 33, 2733-2743, https://doi.org/10.1016/S13522310(98)00362-8, 1999.

Zepp, R. G., Schlotzhauer, P. F., and Sink, R. M.: Photosensitized transformations involving electronic energy transfer in natural waters: role of humic substances, Environ. Sci. Technol., 19, 7481, https://doi.org/10.1021/es00131a008, 1985.

Zhang, D., Yan, S., and Song, W.: Photochemically induced formation of reactive oxygen species (ROS) from effluent organic matter, Environ. Sci. Technol., 48, 12645-12653, https://doi.org/10.1021/es5028663, 2014.

Zhao, R., Lee, A. K. Y., Huang, L., Li, X., Yang, F., and Abbatt, J. P. D.: Photochemical processing of aqueous atmospheric brown carbon, Atmos. Chem. Phys., 15, 6087-6100, https://doi.org/10.5194/acp-15-6087-2015, 2015.

Zhao, Y., Hallar, A. G., and Mazzoleni, L. R.: Atmospheric organic matter in clouds: exact masses and molecular formula identification using ultrahigh-resolution FT-ICR mass spectrometry, Atmos. Chem. Phys., 13, 12343-12362, https://doi.org/10.5194/acp-13-12343-2013, 2013.

Zhong, M. and Jang, M.: Dynamic light absorption of biomass-burning organic carbon photochemically aged under natural sunlight, Atmos. Chem. Phys., 14, 1517-1525, https://doi.org/10.5194/acp-14-1517-2014, 2014.

Zhou, H., Yan, S., Lian, L., and Song, W.: Triplet-State Photochemistry of Dissolved Organic Matter: Triplet-State Energy Distribution and Surface Electric Charge Conditions, Environ. Sci. Technol., 53, 2482-2490, https://doi.org/10.1021/acs.est.8b06574, 2019. 